\title{
Lipid apheresis techniques: current status in Germany
}

\author{
Peter Grützmacher · Claudius Kleinert
}

Published online: 15 May 2012

(C) The Author(s) 2012. This article is published with open access at Springerlink.com

\begin{abstract}
For long-term lipid apheresis therapy, several different technical systems have been developed which enable effective reduction of LDL cholesterol and other atherogenic lipoproteins, such as Lp(a), with sufficient selectivity and good clinical tolerance. Suitable techniques include whole blood adsorption with polyacrylamide and dextran sulfate cellulose, while primary plasma separation is used for cascade filtration, heparin-induced precipitation, immunoadsorption, silicate gel adsorption, and dextran sulfate cellulose (both techniques).

The technical features are described. Only intensive training and experience of the medical personnel guarantees reliable treatment safety of all systems at a very low rate of minor side effects.
\end{abstract}

Keywords Lipid apheresis - Hypercholesterolemia Lipoprotein $a \cdot$ LDL cholesterol

\section{Introduction}

Over the past 3 decades, the lipid apheresis techniques have progressed considerably. At present, 6 different systems are available which have been approved by the technical surveillance institute - called TÜV - and been awarded a so-called CE-sign. All systems now have fully automated process management. A continuous manual steering is no longer necessary.

All methods fulfill the current legal requirements for LDL apheresis, made by the German Gemeinsamer Bun-

P. Grützmacher $(\square) \cdot$ C. Kleinert

Medizinische Klinik 2, Markus Krankenhaus,

Frankfurt/Main, Germany

e-mail: peter.gruetzmacher@fdk.info desausschuss (GBA). More than $60 \%$ LDL reduction has to be achieved per apheresis session within $6 \mathrm{~h}$.

This report focuses on technical aspects of the lipid apheresis technique currently used in Germany.

Although the technical principles of lipid apheresis are basically different, the requirements are easily fulfilled by all techniques, usually within a $1.5-3 \mathrm{~h}$ session. [For review see $3,7,8,11,14,15]$.

The lipid reduction rates of the different techniques are shown in Table 1.

\section{Whole blood apheresis systems}

The progress in adsorber technology has given rise to a considerable simplification of purification techniques. So far, only the adsorption technology is suitable for whole blood apheresis. Adsorbing substances in microporous granula of larger diameters allows the blood to flow through the adsorber without clotting. Heparin and citrate are used for anticoagulation. The buildup is simple; 1.5-2 blood volumes are usually processed.

The principle is also called hemoperfusion, well-known in the treatment of severe intoxication.

\section{Polyacrylamide — adsorption}

With the DALI system (abbreviation for direct adsorption of lipoproteins), negatively charged polyacrylamide is fixed on Eupergit ${ }^{\circledR}$ beads, binding to the positively charged APO B 100 region of LDL, VLDL, and Lp(a) particles. Adsorber sizes range from 300-1,200 ml, manufactured for single use. Citrate is used for anticoagulation. ACE-inhibitor treatment is contraindicated $[1,16]$. 
Table 1 Reduction rates of serum (lipo)proteins with current LDL apheresis systems (according to literature). (Modified from [4])

\begin{tabular}{lcrrrc} 
& Lipid filtration & HELP & DALI & \multicolumn{1}{c}{ DSA } & \multicolumn{1}{c}{ LA } \\
\hline LDL cholesterol (\%) & $61-68$ & $55-61$ & $53-76$ & $49-75$ & $62-69$ \\
HDL cholesterol (\%) & $6-17$ & $5-17$ & $05-29$ & $4-17$ & $9-27$ \\
Lp(a) (\%) & $61-74$ & $55-68$ & $28-74$ & $19-70$ & $51-71$ \\
Triglycerides (\%) & $38-56$ & $20-53$ & $29-40$ & $26-60$ & $34-49$ \\
Fibrinogen (\%) & $42-51$ & $51-58$ & $13-16$ & $17-40$ & $15-21$ \\
IgG (\%) & 14 & 16 & $15-20$ & 11 & 25 \\
\hline
\end{tabular}

\section{Dextran sulfate cellulose adsorption}

More than 20 years before its introduction as a whole blood adsorption technique, dextran sulfate cellulose was (and is still) used for LDL apheresis of plasma. Negatively charged dextran sulfate is fixed on cellulose beads, which is the ligand for the abovementioned lipoproteins.

Different adsorber capacities are available for single use (DL 50, DL 75, DL 100). Citrate is used for anticoagulation; combination with heparin is possible. The use of ACE inhibitors is contraindicated because the membrane generates bradykinine, a potent endogenous vasodilatator which cannot be metabolized when ACE inhibitors are given, resulting in serious hypotensive and anaphylactoid reactions.

\section{Systems with plasma separation}

Since the early days of LDL apheresis, the plasma separation has been used to isolate plasma from blood cells. For plasma separation, hollow capillary fiber filters or centrifuge systems are used. Successful treatment has been described in some patients treated using simple plasma separation for more than 6-9 years, replacing plasma with nearly iso oncotic albumin (5\%) derived from blood donors [13].

Processing the patient's plasma by adsorption, precipitation or a second filtration permits reinfusion of the patient's own plasma, cleared from atherogenic lipoproteins. Within $2-3 \mathrm{~h}, 1-1.5$ plasma volumes are usually processed [2].

\section{Cascade filtration}

This technique requires primary plasma separation; usually a hollow fiber filter is used to separate plasma from blood cells. Plasma is processed through a second hollow fiber filter, permeable for particles with a molecular weight below 50,000-100,000 Da, allowing HDL, albumin, and smaller immunoglobulins to pass, whereas LDL, Lp(a), VLDL and chylomicrones, as well as larger immunoglobulins like IgM, are retained. In contrast to the first decade of lipid apheresis treatment with this technique, improvement in membrane technology has made the loss of HDL and serum proteins, especially serum albumin, negligible. The term lipid filtration was proposed for the use of highly selective filters ( $\mathrm{EC}_{50} \mathrm{~W}$, Diamed company).

Fully automated apheresis machines have been developed so that continuous manual steering of flows and pres- sures is no longer required (Octo Nova/Diamed, Monet/ Fresenius, Germany).

Warming of plasma to $38.5^{\circ} \mathrm{C}$ improves the sieving characteristics of larger lipoproteins compared to HDL. Heparin and citrate or both can be used for anticoagulation. The cascade filters are manufactured for single use $[4,5]$.

\section{Heparin-induced extracorporeal $L \mathrm{DL}$ precipitation (HELP system)}

The HELP system was developed in Germany in the 1980s, using the laboratory technique of determining HDL cholesterol by precipitation of LDL and VLDL at low $\mathrm{pH}$ in the presence of unfractionated heparin. After plasma separation, the plasma is diluted $1: 1$ with $0.2 \mathrm{M}$ sodium acetate buffer ( $\mathrm{pH} 4.85$ ), containing 100,000 IU heparin/L. At a low $\mathrm{pH}$ of 5.12, a heparin-protein complex, consisting of LDL, $\mathrm{Lp}(\mathrm{a})$, fibrinogen and VLDL, precipitates, which is cleared by a polycarbonate precipitation filter; thereafter, heparin is absorbed by a DEAE-cellulose-adsorber. Finally, the low $\mathrm{pH}$ plasma is buffered by a single path bicarbonate hemodiafiltration. For anticoagulation of the blood circulation, fractionated and unfractionated heparin can be used. The size of precipitation filter and adsorber has been increased, now enabling treatment of up to $4 \mathrm{~L}$ of plasma.

Despite the complex procedure, a considerable simplification and shortening of treatment has been achieved by premanufactured devices and fully automated rinsing processes.

The pronounced depletion of fibrinogen (also in cascade filtration) is assumed to have a contributory antiatherogenic potential $[9,10,12]$.

\section{Dextran sulfate cellulose adsorption}

This technique was introduced in Japan in the early 1980s. The adsorption principle has been described above. The system is designed for single use. Adsorption of HDL cholesterol (which has no negatively charged domain) is negligible. A double column system has been developed, switching after every $500 \mathrm{ml}$ of treated plasma volume to the other column, simultaneously flushing the lipoproteinsaturated column with a phosphate buffer for regeneration. Theoretically, the technique permits treatment of an unlimited amount of plasma, which is not possible with whole blood adsorption techniques. Heparin is used for anticoagulation $[14,15]$. 


\section{Silicate gel adsorption}

Recently a plasma adsorption technique using silicate gel granula was introduced. Microporous silicate beads, negatively charged on the surface, bind to the positively charged APO B region of LDL and VLDL, similar to dextran sulfate and polyacrylamide, leaving HDL particles unaffected.

Heparin is used for anticoagulation.

The Adasorb ${ }^{\circledR}$ machine (Medicap Company) is used for plasma processing. For primary plasma separation, several primary units are applicable, such as Cobe Spectra ${ }^{\circledR}$, Life $18^{\circledR}$, requiring the combination of two apheresis units of different distributors.

A double column technique is used, changing the absorber during treatment, with simultaneous regeneration of the saturated adsorber. As a technique for regeneration and disinfection has now been developed, the system can be reused for more than 30 treatments (lipo collect $300^{\circledR}$, Medocon company, Germany).

\section{Immunoadsorption}

Polyclonal antibodies against human APO B100, derived from sheep, are fixed on Sepharose CL-4B, which bind all APO B100-containing lipoproteins (LDL, Lp(a), VLDL) specifically. However, there is considerable nonspecific binding of other plasma proteins.

A double column system is used, changing to the second column after processing of every $500 \mathrm{ml}$ of plasma, simultaneously flushing the saturated column with acid glycine for regeneration.

Production of the columns is expensive. Therefore, the system must be reused for 20-40 sessions per column, two column sizes are available. Heparin and citrates or both can be used for anticoagulation.

After the end of the session, the regenerated columns are filled with antibacterial sodium acid and stored at $4^{\circ} \mathrm{C}$. Careful flushing with isotonic saline is necessary before the next treatment $[3,15]$.

\section{Further specific indications}

For isolated hyperlipoproteinemia (a), all systems are effective because the behavior of $\mathrm{Lp}(\mathrm{a})$ is similar to LDL, which is also part of the $L p(a)$ particle.

Efficient elimination of phytanic acid, which is elevated in the rare Refsum's syndrome, has been described by several systems, such as DALI, HELP, and cascade filtration. Elimination is easily possible because phytanic acid in plasma is largely bound to LDL and VLDL particles [3].

The chylomicronemia syndrome is characterized by a massive increase of triglyceride-rich plasma lipids. Triglyceride levels exceeding 5,000-10,000 mg/dL can be observed. The plasma lipid concentration is $10-20$ fold higher than in LDL apheresis patients.

Absorption techniques are regularly not effective enough due to rapid saturation of the current adsorber. The cascade filtration or even pure plasma exchange is superior in these cases.

\section{Safety of apheresis techniques}

The observation of side effects in clinical studies is usually based on very low number of patients and treatments. Much more experience has been gathered by monitoring the routine treatment, initiated by the manufacturers in cooperation with apheresis specialists [for review see $3-5,7,9,11$, 14-16, and Table 2].

In general, the lipid apheresis is well tolerated and procedures are safe. Lethal events have not been published.

Serious complications are rare, ranging from $<0.1 \%$ $<1 \%$. Allergic reactions, fever, dyspnea, cardiac arrhythmias, hemolysis, and shock have been documented as rare events.

Although blood coagulation is deeply disturbed for several hours after apheresis, more or less by all systems, bleeding complications have not been reported [15].

Table 2 Common side effects of lipid apheresis treatment $[1,3-7,9,11,12,15,16]$

\begin{tabular}{|c|c|c|c|c|}
\hline Method & Treatment records & $\begin{array}{l}\text { Total incidence } \\
(\%)\end{array}$ & $\begin{array}{l}\text { Frequent/less severe } \\
\text { side effects }\end{array}$ & Associated symptoms \\
\hline HELP & 75,061 & 3.05 & $\begin{array}{l}\text { Hypotension, angina, hea- } \\
\text { dache, nausea, weariness, } \\
\text { edema, eye pressure }\end{array}$ & $\downarrow$ Coagulation \\
\hline Cascade-filtration & 1,708 & 2 & $\begin{array}{l}\text { Hypotension, fatigue, } \\
\text { edema }\end{array}$ & $\begin{array}{l}\text { Protein loss (not with } \\
\mathrm{EC}_{50} \text { ) }\end{array}$ \\
\hline DALI & 12,291 & 3.85 & $\begin{array}{l}\text { Hypotension, nausea, } \\
\text { vomiting, chest pain, flush }\end{array}$ & $\uparrow$ Bradykinine \\
\hline $\begin{array}{l}\text { Dextran sulfate } \\
\text { adsorption }\end{array}$ & Not reported & $0.3-0.9$ & $\begin{array}{l}\text { Hypotension, paresthesias, } \\
\text { pain, nausea, vertigo }\end{array}$ & $\begin{array}{l}\uparrow \text { Bradykinine, } \downarrow \\
\text { coagulation }\end{array}$ \\
\hline Immunoadsorption & 2,600 & $<2$ & $\begin{array}{l}\text { Hypotension, nausea, } \\
\text { vertigo }\end{array}$ & Antibodies (sheep), reuse \\
\hline
\end{tabular}

Serious complications are rare and severe, ranging $<0.1 \%{ }_{0}-<1 \%$, usually causing hospital admission

Allergic reaction $0.25 \%$, fever $0.2 \%$, hemolysis $0.05 \%$, dyspnea $0.1 \%$, shock $0.2 \%$, arrhythmia $0.04 \%$ 
In general, the patients should be instructed to report any changes in medication immediately before the next treatment sessions since an unexpected risk may occur if the medication is changed, e.g. by cardiologists or general practitioners, introducing ACE-inhibitors which are contraindicated for most adsorption techniques (see above). Here the use of renin inhibitors and AT1 antagonists is recommended.

Mild hypotension occurs occasionally, usually resolved after the end of treatment, and may be accompanied by nausea, vertigo, fatigue, mild headache and vomiting. This mild cardiocirculatory instability is mostly induced by the extension of plasma volume to the extracorporeal circuit; moderate loss of serum proteins may aggravate symptoms and can lead to mild edema when higher volumes of saline infusions are used. However, in all currently used systems a minor loss of proteins no longer requires albumin substitution and is no longer of clinical relevance.

A nonspecific loss of $\gamma$-globulins in the range of $5-10 \%$ occurs, but there is no evidence of increased susceptibility to infections. In routine practice, an apheresis session is often scheduled some days later in the patients with active infections.

In patients with immunoadsorption, the sheep antibodies to human APO B can be detected, not inducing any clinical diseases.

An additional filter behind the adsorber is used in some plasma apheresis systems to enhance protection from unwanted contamination of reinfused patient plasma with microparticles from the adsorber; however, this is not possible when whole blood adsorption systems are applied.

Meanwhile, all the systems have fully automated process monitoring, which protects from most procedural complications. However, the technical principles are complicated and require a thorough understanding of the underlying physical processes.

Intensive training of medical staff including physicians is mandatory to maintain treatment safety since none of the systems offers protection from malpractice through inexperienced staff.

For ambulatory treatment, a special experience with extracorporeal therapy and dialysis, as well as a specialist medical qualification in nephrology, is required by German law.

In clinical settings, some apheresis procedures are often performed by bloodbanks, which have highly experienced and qualified staff for the processing of blood and plasma products.

Conflict of interests The author has accepted fees from the companies B. Braun and Fresenius, Germany. This article is part of a supplement sponsored by an unrestricted educational grant from B. Braun and Fresenius Medical Care.
Open Access This article is distributed under the terms of the Creative Commons Attribution License which permits any use, distribution and reproduction in any medium, provided the original author(s) and source are credited.

\section{References}

1. Bosch T, Lennertz A, Schenzle D, Dräger J (2002). Direct adsorption of low-density lipoprotein and lipoprotein(a) from whole blood: results of the first clinical long-term multicenter study using DALI apheresis. J Clin Apheresis 17:161-169

2. Fridey JL, Kaplan AA (2009) Prescription and technique of plasma exchange uptodate-online 2009

3. Heibges A, Fassbender C, Klingel R (2010) Akt. Praxis der Lipidapherese, Nieren- und Hochdruckkrankheiten 39:322-337

4. Klingel R, Fassbender R, Fassbender C, Göhlen B (2003) From membrane differential filtration to lipid filtration: technological progress in low-density lipoprotein apheresis. Ther Apher Dial 7:350-358

5. Messner H, Godehardt E, Köbberling J, Hein D (1993) Membrane diffetential filtration in extracorporeal LDL-cholesterol elimination. In: Gotto AM, Mancini M, Richter WO, Schwandt P (eds) Treatment of servere dyslipoproteinemia in the prevention of coronary heart disease. Basel, Karger, pp 204-207

6. Richter WO, Donner MG, Hofling B, Schwandt P (1998) Longterm effect of low-density lipoprotein apheresis on plasma lipoproteins and coronary heart disease in native vessels and coronary bypass in severe heterozygous familial hypercholesterolemia. Metabolism 47:863-868

7. Parhofer KG (2010) Dyslipoproteinämien — Strategien zur Diagnostik und Therapie, 3. Aufl. Uni-MED-Verlag, Bremen

8. Rosenson RS (2011) Treatment of drug-resistant hypercholesterolemia uptodate-online 2011

9. Schuff-Werner P (2001) Diagnostik und Therapie der Dyslipoproteinämien-Heparin-induzierte extrakorporale LDL-Präzipitation (HELP). In: Schwandt P, Richter WO, Parhofer KG (eds) Handbuch der Fettstoffwechselstörungen. Schattauer, Stuttgart, pp 538-556

10. Schuff-Werner P, Gohlke H, Bartmann U (1994) The HELPLDL-apheresis multicentre study, an angiographically assessed trial on the role of LDL apheresis in the secondary prevention of coronary heart disease. II. Final evaluation of the effect of regular treatment on LDL-cholesterol plasma concentrations and the course of coronary heart disease. The HELP-Study Group. Heparin-induced extra-corporeal LDL-precipitation. Eur J Clin Invest 24:724-732

11. Schwandt P, Parhofer KG (2007) Handbuch der Fettstoffwechselstörungen, 3 edn. Schattauer Verlag

12. Seidel D (1994) HELP report-10 years of clinical experience. MMV Medizin Verlag, München

13. Thompson GR, Maher VM, Matthews S et al (1995) Familial hypercholesterolemia regression study: a randomized trial of lowdensity-lipoprotein apheresis. Lancet 345:811-816

14. Thompson GR (2008) HEART-UK LDL Apheresis Working Group. Recommendations for the use of LDL apheresis. Atherosclerosis 198(2):247-255

15. Thompson GR (2003) LDL apheresis. Atherosclerosis 167(1): $1-13$

16. Wendler T, Schilling R, Lennertz A, Sodemann K, Kleophas W, Meßner H, Riechers G, Wagner J, Keller C, Bosch T (2003) Efficacy and safety of DALI LDL-apheresis at high blood flow rates: a prospective multicenter study. J Clin Apheresis 18:157-166 